\title{
An intense source for cold cluster ions of a specific composition
}

Cite as: Rev. Sci. Instrum. 91, 033315 (2020); https://doi.org/10.1063/1.5133112

Submitted: 24 October 2019 . Accepted: 26 February 2020 . Published Online: 16 March 2020

(D) L. Tiefenthaler, (D) J. Ameixa, P. Martini, S. Albertini, (D) L. Ballauf, M. Zankl, M. Goulart, (D) F. Laimer, (D) K. von Haeften, (D) F. Zappa, and (iD) P. Scheier

\section{ARTICLES YOU MAY BE INTERESTED IN}

\section{Sizes of large He droplets}

The Journal of Chemical Physics 135, 154201 (2011); https://doi.org/10.1063/1.3650235

A high sensitivity, high resolution tandem mass spectrometer to research low-energy, reactive ion-surface interactions

Review of Scientific Instruments 91, 065101 (2020); https://doi.org/10.1063/1.5145170

Isotope enrichment in neon clusters grown in helium nanodroplets

The Journal of Chemical Physics 153, 164305 (2020); https://doi.org/10.1063/5.0028056

\section{Challenge us.}

What are your needs for periodic signal detection?

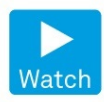

Zurich

- Instruments

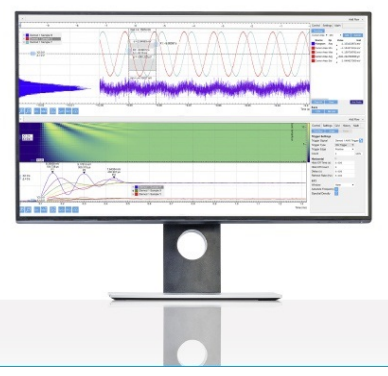

Rev. Sci. Instrum. 91, 033315 (2020); https://doi.org/10.1063/1.5133112

91, 033315 


\title{
An intense source for cold cluster ions of a specific composition
}

\author{
Cite as: Rev. Sci. Instrum. 91, 033315 (2020); doi: 10.1063/1.5133112 \\ Submitted: 24 October 2019 - Accepted: 26 February 2020 • \\ Published Online: 16 March 2020
}

\author{
L. Tiefenthaler, \\ J. Ameixa, \\ P. Martini, ${ }^{\prime}$ S. Albertini, ${ }^{1}$ L. Ballauf, \\ M. Zankl,' M. Goulart, ${ }^{1}$ F. Laimer, \\ K. von Haeften, \\ F. Zappa, \\ and P. Scheier, a) (iD
}

\author{
AFFILIATIONS \\ ${ }^{1}$ Institut für Ionenphysik und Angewandte Physik, Universität Innsbruck, Technikerstr. 25, A-6020 Innsbruck, Austria \\ ${ }^{2}$ Laboratório de Colisões Atómicas e Moleculares, CEFITEC, Departamento de Física, Faculdade de Ciências e Tecnologia, \\ Universidade NOVA de Lisboa, Campus de Caparica, 2829-516 Caparica, Portugal \\ ${ }^{3}$ Kanano $\mathrm{GmbH}$, Sedanstr. 14, 89077 UIm, Germany \\ ${ }^{4}$ Departamento de Física, Instituto de Ciências Exatas, Universidade Federal de Juiz de Fora, 36036330 Juiz de Fora, MG, Brazil
}

\begin{abstract}
a) Author to whom correspondence should be addressed: paul.scheier@uibk.ac.at
\end{abstract}

\begin{abstract}
The demand for nanoscale materials of ultra-high purity and narrow size distribution is addressed. Clusters of $\mathrm{Au}, \mathrm{C}_{60}, \mathrm{H}_{2} \mathrm{O}$, and serine are produced inside helium nanodroplets using a combination of ionization, mass filtering, collisions with atomic or molecular vapor, and electrostatic extraction, in a specific and novel sequence. The helium droplets are produced in an expansion of cold helium gas through a nozzle into vacuum. The droplets are ionized by electron bombardment and subjected to a mass filter. The ionic and mass-selected helium droplets are then guided through a vacuum chamber filled with atomic or molecular vapor where they collide and "pick up" the vapor. The dopants then agglomerate inside the helium droplets around charge centers to singly charged clusters. Evaporation of the helium droplets is induced by collisions in a helium-filled radio frequency (RF)-hexapole, which liberates the cluster ions from the host droplets. The clusters are analyzed with a time-of-flight mass spectrometer. It is demonstrated that using this sequence, the size distribution of the dopant cluster ions is distinctly narrower compared to ionization after pickup. Likewise, the ion cluster beam is more intense. The mass spectra show, as well, that ion clusters of the dopants can be produced with only few helium atoms attached, which will be important for messenger spectroscopy. All these findings are important for the scientific research of clusters and nanoscale materials in general.
\end{abstract}

Published under license by AIP Publishing. https://doi.org/10.1063/1.5133112

\section{INTRODUCTION}

Nanostructured materials gain increasing importance because of their unique properties associated with their small size. These properties are relevant for many applications and have found entry into a growing number of consumer products. Some of their smallsize-related properties stem from the surface to bulk ratio, which increases with a decrease in size, making the particles more susceptible for their environment. For very small particles, for example metal clusters consisting of up to a few dozen atoms, it has also been observed that electronic properties ${ }^{1,2}$ as well as chemical reactivity $^{3-11}$ can change rather dramatically by only the addition or removal of a single atom. Owing to these features, metal clusters are in the focus of material science and a number of different production techniques have emerged from this research activity. ${ }^{12,13}$ In order to perform reasonably insightful experiments into how the properties of matter develop with the number of constituents, these production techniques must provide sufficient control of size. Experiments with mass-selected clusters are of paramount importance in this context. Another important aspect in cluster production is purity. Many chemical nanoparticle synthesis protocols require the capping of metal nanoparticle surfaces with stabilizing agents, thus limiting their purity.

The cluster production method can be categorized into topdown or bottom-up approaches, i.e., the clusters are produced either via fragmentation of bulk matter ${ }^{16}$ or by condensation of individual atoms or molecules, ${ }^{1}$ respectively. While both strategies lead to clusters that often span a large size range and usually follow a 
$\log$-normal ${ }^{17}$ distribution, bottom-up approaches have the specific advantage to "build" clusters atom by atom. Also, it is possible to subject them to size-selecting filters.

Mass spectrometry is a common method of choice to select a specific cluster size, but it requires ions. ${ }^{18-22}$ Methods such as discharges, ${ }^{23,24}$ magnetron sputtering, ${ }^{25-31}$ or laser vaporization ${ }^{32}$ immediately form, at least in part, charged clusters that are readily accessible for mass spectrometry. The majority of the material used for the production of the neutral clusters, however, is wasted in the form of unwanted cluster sizes or becomes coatings on the walls inside the cluster source.

The so-called "pickup method" is a bottom-up cluster production method that provides some size selectivity via sequential growth of atoms. A beam of comparatively large clusters or droplets in vacuum is passed through a region filled with atomic or molecular vapor. When passing through this region, the large clustersoften rare gas clusters-collide with the atoms in the vapor. Because of the low temperature of the host clusters, the atoms stick to the surface of the clusters and are carried downstream; hence, it is said that they have been "picked up." The pickup method has been reported first by Gough and co-workers for $\mathrm{SF}_{6}$ doped argon clusters.

For large vapor pressures in the pickup region, it is possible for the clusters to undergo multiple pickup events. If liquid helium nanodroplets (HNDs) are used, each pickup event is followed by migration of the dopants through the liquid droplets until they encounter other dopants and agglomerate. The process of agglomeration in such a way is governed by differential equations whose solutions are Poisson functions $P_{k}(n)$ of the "dopant-cluster" size $k$ and the vapor density $n$. Helium droplets ${ }^{34,35}$ have been known to be able to pick up vapors of various materials (metals, molecular vapors, etc.) and are nowadays considered as an established route to form clusters without the use of any other solvent. Hence, exceptional purity can be achieved. The low temperature $\left(0.37 \mathrm{~K}^{36}\right)$ inside the droplets and the enormous cooling rate of liquid He of at least $10^{10} \mathrm{~K} / \mathrm{s}^{37}$ provide an environment for obtaining interesting mixtures of various species, including geometries far from thermodynamic equilibrium. ${ }^{38-43}$ The timescale of dopant cluster formation is a few $\mu$ s, which reduces the risk of contamination with impurities from the residual gas in the vacuum chamber rather effectively in contrast to other recently developed matrix-assisted methods. ${ }^{44}$

Furthermore, mass selection using ion-mass-filters has been explored. Unfortunately, as mass selection requires ionization of the initially neutral clusters, this type of "post-mass-filtering" leads to substantial fragmentation and annealing of the clusters obtained by pickup. Among other drawbacks is a substantial drop in the yield, making experiments using mass-selected clusters rather cumbersome.

In view of these difficulties, it is highly desirable to develop alternatives, including techniques by which the average size can be narrowed prior to the pickup process. While the Poisson-shaped size distribution of clusters produced by pickup is well understood, ${ }^{34}$ the log-normal size distribution of the neutral helium droplets means that the Poisson size distribution will be further broadened. Ionizing the helium droplets prior to the pickup region presents an opportunity to size-select them in a suitable mass-filter, thus limiting the size range in the resulting cluster size distribution of the dopants.
An added value of this approach is that the cluster size can now be controlled by variation of the pass-through mass of the filter, in addition to the vapor pressure in the pickup cell. This variability will be particularly important when very large droplets in the size range of up to $10^{10}$ are used because their size distribution can be particularly wide owing to that they have been produced by fragmentation of liquid helium. Also, it is difficult to extract embedded clusters from such large droplets using electric fields.

In this paper, we will report on a novel helium droplet setup in which the sequence of ionization and pickup has been altered. In the presented setup, neutral droplets are produced, ionized, mass-percharge-selected in an electrostatic field, and passed through a pickup region. The clusters grown inside the ionic, mass-selected droplets are then extracted and analyzed using a time-of-flight (TOF) mass spectrometer. We compare the results of the present setup with the ones available in the literature for different dopant examples: gold, $\mathrm{C}_{60}$, water, and serine. For instance, we show that by using this sequence, gold clusters can be produced at much larger intensity, approximately two orders of magnitude compared to our previous setup. In addition, we observe a changed size distribution of the gold clusters. Compared to our previous instrument, the oddeven alterations as well as magic numbers due to electronic shell closure have vanished. We also observe that the extraction of cluster ions from the large helium droplets facilitated by the new setup results in a more narrow size distribution of the detected dopant cluster ions. Our paper will be important for the advance of scientific research of clusters, particularly, where better control of size is important while maintaining greatest possible cluster composition flexibility.

\section{THE HELIUM DROPLET SOURCE FOR CHARGED DOPANT CLUSTERS}

\section{A. Current state of the art}

The standard sequence of events for many experiments dealing with doped HNDs consists of helium droplet production, followed by dopant pickup by the neutral droplets, ionization by electron impact, and subsequent mass spectrometry. The production of helium droplets from pre-cooled supersonic beams is a wellestablished technique, ${ }^{35,36,46-48}$ but every research group has its own special design. ${ }^{4-57}$ The droplet formation in free jet expansions is highly dependent on the temperature and pressure of the stagnating gas. For typical pressures around $2 \mathrm{MPa}$ and temperatures above $10 \mathrm{~K}$, the formation is thought to occur via condensation of the gas, ${ }^{58}$ leading to droplets containing up to $10^{4}$ helium atoms. ${ }^{57}$ For temperatures below $10 \mathrm{~K}$, the droplets are formed via fragmentation of helium that liquefies near the nozzle, resulting in sizes up to several billion helium atoms. ${ }^{36,59}$

Dopant vapor is picked up by HNDs upon collisions in a stochastic way, with a probability proportional to the geometrical cross section of the HND. The wider the neutral helium droplet size distribution is, the wider the dopant cluster size distribution will be. The collision of a gas phase dopant and its agglomeration inside a HND releases energy, which is removed via evaporation of helium atoms. In the case of gold, for example, the average center of mass collision energy at an oven temperature of $1300 \mathrm{~K}$ and a velocity of the He droplet of typically $200 \mathrm{~m} / \mathrm{s}^{60}$ is $0.16 \mathrm{eV}$. The binding energy 
of each atom to a gold cluster is in the range of $2.6 \mathrm{eV}-4.7 \mathrm{eV}$. ${ }^{61}$ With a binding energy of a $\mathrm{He}$ atom to a droplet of $0.6 \mathrm{meV}$, every addition of a gold atom is expected to result in the loss of 5000 to $8300 \mathrm{He}$ atoms. When the number of atoms in a given droplet is very large, its size is largely unaltered by the pickup events, but when it is small, the pickup events shrink the droplets, lowering the geometrical cross section until the pickup process self-terminates.

The probability for an electron to collide with a helium droplet also scales approximately as the geometrical cross section, which can be up to several thousand square nanometers. ${ }^{62-64}$ Ionization of neutral dopant clusters inside the helium droplet after electron impact may occur via different routes, depending on the nature of the interaction between the dopant and the helium environment. When the dopant resides deep inside the droplet, ionization occurs via charge exchange with an ionized helium atom, and the energy threshold appears close to the ionization energy of helium. $\mathrm{He}^{+}$ production may occur anywhere in the droplet and the cross section for this process scales with the geometric cross section of the droplet. According to the literature, polarization of the dopant by the initially formed $\mathrm{He}^{+}$ion leads to a long-range electrostatic interaction and the charge approaches the dopant via resonant holehopping. ${ }^{65,66}$ If the dopant is not reached after about ten hops, vibrationally excited $\mathrm{He}_{2}{ }^{+}$is formed that may be ejected from the droplet or transfers its charge to the dopant. The energy difference between the ionization energy of helium (as well as $\mathrm{He}_{2}$ ) and the ionization energy of the dopant cluster (often exceeding $10 \mathrm{eV}$ ) is transferred to the dopant cluster. Energy redistribution into vibrational degrees of freedom leads to the fragmentation of the dopant clusters ${ }^{67}$ unless the surrounding He matrix can quench the excess energy fast enough. Monomer evaporation of excited cluster ions strongly depends on the binding energy of a specific cluster, and the yield of particularly stable clusters is enhanced compared to less stable cluster sizes. This results in intensity anomalies, often called magic numbers. The cluster size distributions of all dopant cluster ions formed upon electron ionization of neutral doped HNDs exhibit magic numbers that are identical to the values found in the literature for the same cluster ions formed without HNDs. ${ }^{35}$ The presence of magic numbers in mass spectra from doped HNDs is a clear indication that excited dopant cluster ions cannot be quenched completely by the surrounding helium.

Heliophobic dopants reside at the surface of the droplet and may be directly hit by the incoming electron, in which case the energy threshold appears close to the dopant ionization energy. The cross section for this process, however, does not benefit from the large size of the helium droplet to which the dopant is attached and, therefore, contributes very little to the signal. Another ionization mechanism is the interaction of the dopant with an electronically excited, metastable helium atom leading to Penning ionization, in which case the energy threshold appears close to the first excitation energy of helium. Metastable helium is also heliophobic, and thus, this process preferentially occurs when the dopant is at or close to the surface.

Very recently, our group has discovered the formation of highly charged HNDs upon electron ionization. ${ }^{68}$ When the droplet source is operated at temperatures close to $4 \mathrm{~K}$, micrometer-sized droplets are formed that are able to carry several thousand charges.
Coulomb repulsion between the charge centers and their high mobility in liquid He lead to minimum energy configurations of the ions at the surface of the HND which can be considered as two-dimensional Coulomb crystals ${ }^{69-71}$ located close to the surface of the droplets. This observation led us to speculate whether multiply charged HNDs would be capable of capturing dopants in a similar fashion as their neutral counterparts do. Each charge center is polarizing neutral dopants and thereby acts as a seed for dopant cluster growth. The regular arrangement of the charges is expected to lead to a uniform growth of many charged dopant clusters in a single multiply charged droplet, increasing the efficiency of dopant cluster ion production substantially. However, these dopant cluster ions are embedded in a massive HND and, thus, are inaccessible for mass spectrometers unless they are extracted from them.

In Sec. II B, an experimental setup is described in detail that enables efficient formation of a narrow size range of dopant cluster ions upon pickup into charged HNDs. Dopant cluster size distributions for several showcases are determined by utilizing mass spectrometry, which demonstrates the versatility of this method. The new instrument is capable of producing ions that are tagged with a few He atoms, which opens exciting future possibilities for messenger type spectroscopy.

\section{B. Helium droplet production}

In the following, we describe the details of our specific source. Figure 1 shows a rendering of a cutaway view of the source (see also the cross section in Fig. 2). High pressure (2 MPa) helium gas of high purity $(99.9999 \%$, Linde $\mathrm{Gas} \mathrm{GmbH}$ ) is pre-cooled by contact with the low temperature stage of a closed-cycle helium cryostat (Sumitomo Heavy Industries, Ltd. RDK-408D2, connected to a compressor F-50, first stage cooling power: $40 \mathrm{~W}$ at $43 \mathrm{~K}$, second stage cooling power: $1 \mathrm{~W}$ at $4.2 \mathrm{~K}$, and minimum temperature $<3.5 \mathrm{~K}$ ). All particulate impurities, as well as condensable gases, are removed by an inline filter (SS-4FWS-VCR-05, pore size $0.5 \mu \mathrm{m}$ ) also attached to the cryostat. Finally, the gas line runs into a cylindrical block made of oxygen-free copper (Montanwerke Brixlegg MB-OF101 with a residual-resistance ratio, $R R R>200$ ) that is directly mounted to the second cooling stage.

Pressurized $\mathrm{He}$ expands continuously through a platinum/ iridium 95\%/5\% pinhole nozzle $(5 \mu \mathrm{m}$ nominal diameter, Plano $\mathrm{GmbH}, \mathrm{A} 0200 \mathrm{P}, 5.67 \mu \mathrm{m}$ exact diameter determined by the scanning electron microscopy) into a vacuum chamber pumped by a turbomolecular pump (Pfeiffer TPU 1600, 1450 l/s pumping speed for $\mathrm{He}$ ). The turbopump is backed by using an oil-free roughing pump (Pfeiffer ACP 40) maintaining a base pressure during operation in the range of $10^{-2} \mathrm{~Pa}$. Without helium, the residual gas pressure is $10^{-6} \mathrm{~Pa}$. The temperature of the helium before expansion is measured with a silicon diode (Lakeshore DT-670 in CU package) attached closely to the nozzle and used as an input for a PID regulator (Lakeshore Temperature Controller Model 335) that controls a heater (Ohmite Resistor 825F25RE, $25 \Omega$ ). This allows us to operate the source between $4.2 \mathrm{~K}$ and $25 \mathrm{~K}$ with $\pm 0.1 \mathrm{~K}$ precision.

The expanding free jet, in which the helium droplets are formed, passes through a $0.5 \mathrm{~mm}$ skimmer (Beam Dynamics, Inc.) positioned about $5 \mathrm{~mm}$ from the nozzle. A home-built vacuum tight shutter, mounted into a CF-200 flange, can separate the helium 


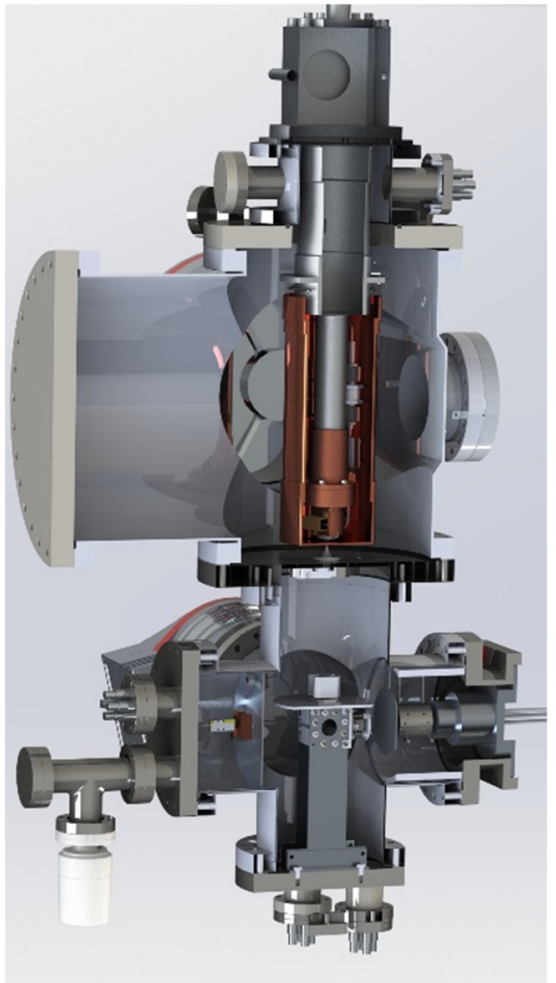

FIG. 1. Rendering of the helium nanodroplet source module inside the vacuum chamber with a cutaway view.

droplet source from the rest of the instrument. Thus, warming up the cluster source is not required for maintenance of the ion source or pickup chambers.

Thermal contraction of the cold head when cooling from room temperature to a few kelvin may lead to a lateral displacement of the nozzle with respect to the opening of the skimmer. In order to compensate for this effect, the complete cold head is placed on a Viton ring and can be moved with two orthogonal pairs of adjusting screws.

\section{Droplet ionization}

After passing the skimmer, the helium droplet beam enters a differentially pumped vacuum chamber. This contains an electron impact ion source, an energy filter to select or scan the charged droplets with respect to their mass-per-charge ratio $(\mathrm{m} / \mathrm{z})$, and a channel electron multiplier detector to measure the yield of the charged droplets and to determine droplet size $(\mathrm{m} / \mathrm{z})$ distributions. For intense ion yields, a conversion dynode in front of the secondary electron multiplier (SEM) can be operated as a Faraday cup. Opposite to these detectors, there are pickup cells for dopant vapor and ion optics to transfer charged droplets into an RF-hexapole taken from a commercial Quadrupole TOF (Q-TOF) mass spectrometer (Q-TOF Ultima from Micromass, Waters). The ion-source chamber is kept at pressures below $10^{-4} \mathrm{~Pa}$ by using a $700 \mathrm{l} / \mathrm{s}$ turbomolecular pump backed with an oil-free roughing pump. The ion source is of Niertype configuration, where the neutral droplet beam is crossed with an electron beam. The electron beam current used in our experiments ranges between $1 \mu \mathrm{A}$ and $2 \mathrm{~mA}$, and the electron energy can be adjusted for an optimal ion signal from close to zero $\mathrm{eV}$ up to $200 \mathrm{eV}$, with an energy spread of about $\pm 0.5 \mathrm{eV}$. The electron energies at about $2 \mathrm{eV}$ and $22 \mathrm{eV}$ are most suitable for obtaining negatively charged droplets, ${ }^{60,72-74}$ but we will not address this possibility in the present paper.

\section{Droplet mass-per-charge selection}

The trajectories of charged droplets can be easily influenced by using static electric fields. Several geometries are possible, such as parallel plates, cylindrical, or spherical sector fields. In fact, we have explored most of them in our laboratory, and a configuration that proved particularly useful is that of the quadrupole bender. With such a configuration, depicted in Fig. 3, a simple polarity reversal

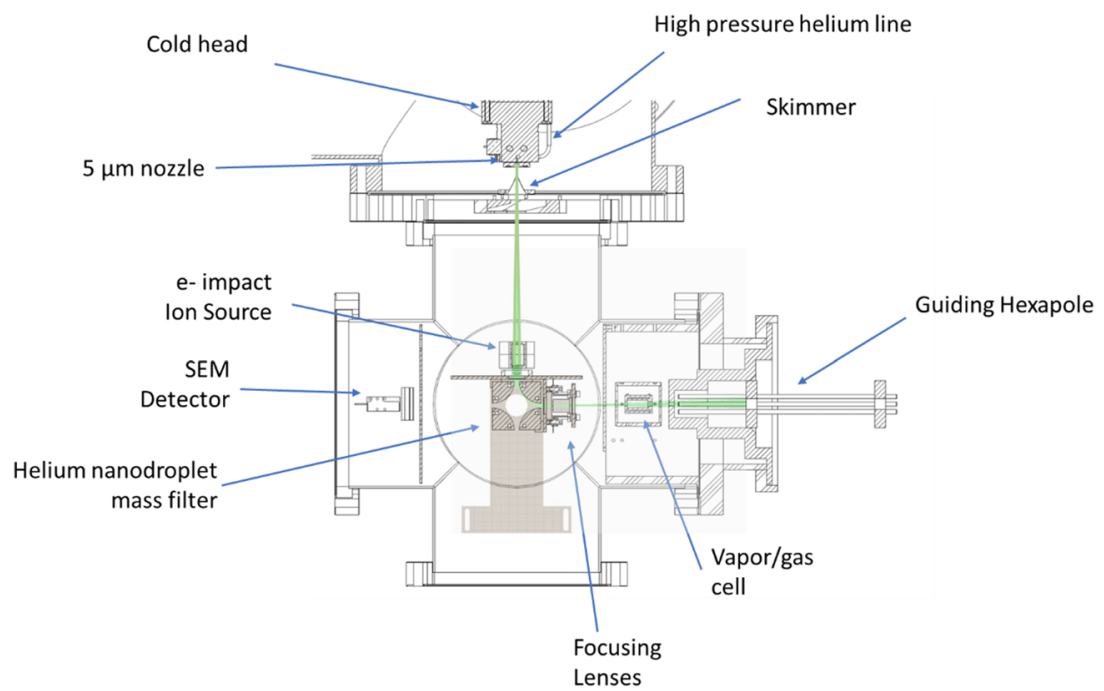

FIG. 2. Cross-sectional view of the apparatus. The green lines represent possible trajectories of the helium droplets from the nozzle, through the ion source, the quadrupole bender, ion optics, and finally through a pickup cell into an RF. hexapole. Actual trajectories were simulated in SIMION (see the text). The simulation was used to determine the helium droplet size as a function of the voltages applied on the electrostatic quadrupole bender. Polarities on the quadrupole can be reversed in order to direct the charged HNDs into the SEM detector. 
a)

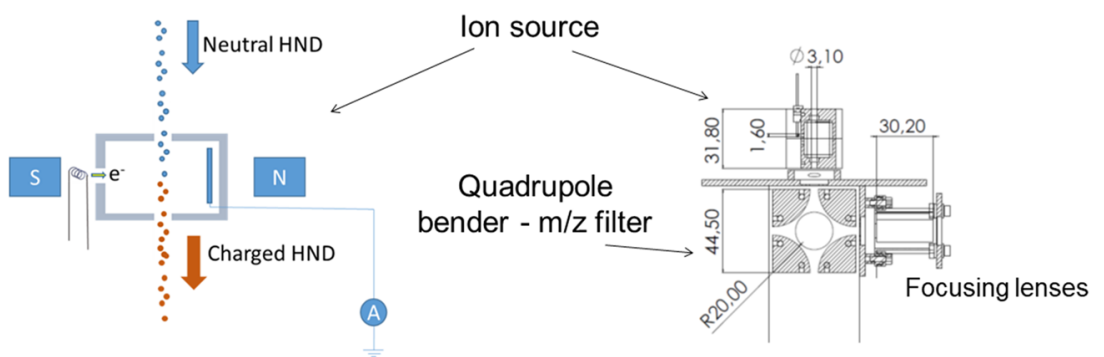

FIG. 3. (a) Schematic view of the electron impact ion source. (b) Close up of the ion source, quadrupole bender that acts as a mass-per-charge filter for ionized HNDs, and focusing lenses. allows us to direct the charged nanodroplet beam either in the direction of a standard secondary electron multiplier and a Faraday cup for ion current determination or in the direction of the pickup cell where the droplets will be doped.

The quadrupole in our experiment was designed with SIMION and its ability to select the kinetic energy per charge of the droplets was simulated assuming a rectangular size distribution of singly charged nanodroplets originating from the nozzle, covering the whole range expected for our cryostat conditions. For each tested voltage configuration, we recorded the kinetic energies of the particles that fell within the acceptance angle of the detector. These particles follow approximately a normal distribution, as can be seen in Fig. 4(a). In Fig. 4(b), we plot the average kinetic energy of such particles for any given quadrupole voltage. The standard deviation of each distribution is plotted as the error bar. As expected, the kinetic energy of the droplets depends linearly on the voltage applied to the quadrupole rods.

As we have already mentioned, droplets obtained from a supersonic beam often exhibit a very narrow velocity spread, with speed ratios which can be up to several hundreds; ${ }^{58,75}$ however, for helium jets produced by fragmentation of liquid helium, the speed ratio may be as low as $10 .^{76}$ The actual velocity is dependent on the He temperature and has been determined for different temperatures by Henne et al. ${ }^{60}$ This correlation between the average cluster speed and $\mathrm{He}$ temperature permits us to convert the kinetic energy per charge of Fig. 4(b) to mass per charge, or equivalently as the number of $\mathrm{He}$ atoms per unit charge, and this will be used throughout the rest of the paper. ${ }^{64,77,78}$

\section{E. Pickup cell}

For dopants that have a low vapor pressure (e.g., $\mathrm{Au}, \mathrm{C}_{60}$, or serine), we constructed an ohmically heated oven that can reach more than $1500 \mathrm{~K}$. This pickup cell consists of an oven and two heat shields, designed to protect the rest of the apparatus from the heat without sacrificing the pumping speed. The oven is made of two concentric SHAPAL-M ceramic tubes of $20 \mathrm{~mm}$ in length, aligned coaxially with the nanodroplet principal trajectory. The inner tube has an inner diameter of $10 \mathrm{~mm}$, where a small amount of sample can be introduced. Around this tube, a tantalum wire of $1 \mathrm{~mm}$ diameter is wrapped in a helical shape around the inner tube. The outer ceramic tube secures the tantalum wire. In our tests with gold, we were able to obtain a sufficient vapor pressure while operating at a moderate heating power slightly above $120 \mathrm{~W}$.

\section{F. Removal of excess helium}

After the helium droplet beam passes through the pickup cell, it enters another chamber equipped with a gas inlet and an RFhexapole ion guide. In order to prevent the exchange of helium with other solvents, ultra-clean $\mathrm{He}$ [99.9999\% purity, Linde Gas GmbH, and additionally purified in a filter (SS-4FWS-VCR-05, pore size $0.5 \mu \mathrm{m}$ ) attached to the cryostat] has to be used. The gas pressure in the hexapole region can be controlled by using a PID regulator, developed together with a specialized company, ${ }^{75}$ to maintain a differentially pumped and adjustable constant pressure at room temperature. The operational range of pressures that can be used in the
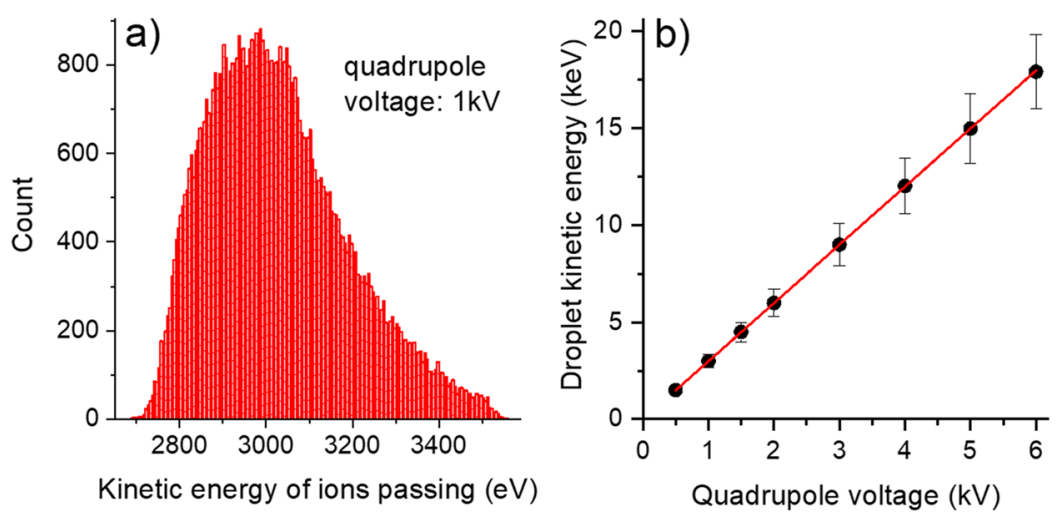

FIG. 4. (a) Simulated intensity distribution of singly charged ions passing through a quadrupole bender with the voltage difference (quadrupole voltage at the rods) set to the rods of $1 \mathrm{kV}$. For each kinetic energy, 1000 ion trajectories were run. (b) Kinetic energies of singly charged helium droplets passing through the quadrupole as a function of the total voltage applied. The $y$-value of the points was determined from the average values obtained from the simulations. The error bars indicate the widths of the energy distributions. 


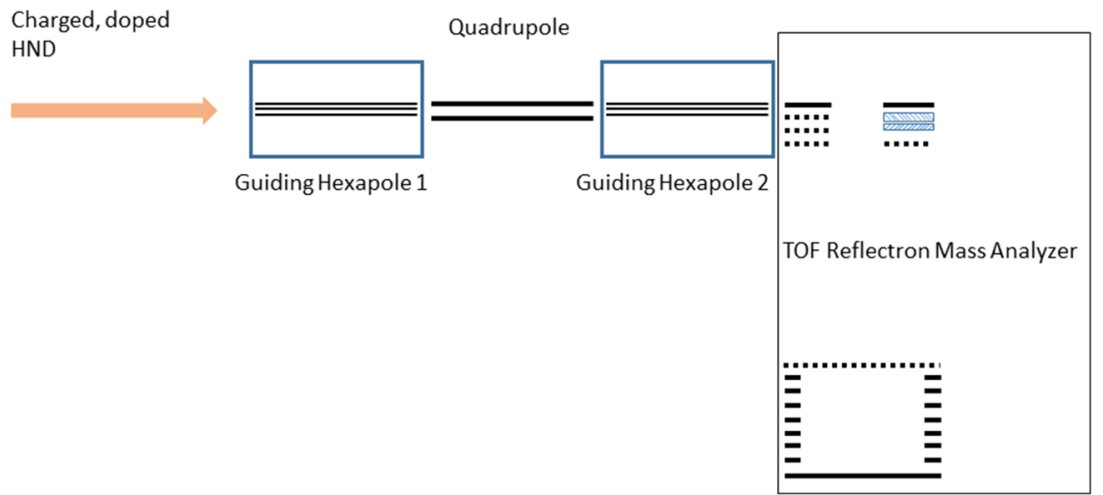

Fig. 5. Schematics of a Q-TOF Ultima mass spectrometer, from Micromass (Waters). The first guiding hexapole is differentially pumped, and it is the region where room temperature $\mathrm{He}$ is introduced in order to evaporate the host helium droplets to extract the embedded singly charged dopant clusters. In this instrument, the TOF reflectron mass analyzer is operated with a drift voltage of $9.1 \mathrm{kV}$. collision cell is limited to $3 \mathrm{kPa}$ because of the leak rate of the collision gas to the rest of the equipment through the openings for the ion beam path.

Evaporation of the droplets is expected due to collisions with the gas and, therefore, a function of pressure. ${ }^{57}$ The hexapole RF potential confines the ion beam in the axial direction as the droplets shrink and low-mass ions are liberated. The hexapole operates with a DC component on its axis that determines the potential energy of the clusters when evaporation of the helium droplet is completed. This DC potential, therefore, translates into the kinetic energy of the ions through the rest of the instrument. Adding traces of another gas to the helium provides the possibility to solvate cluster ions with a small number of selected atoms or molecules.

\section{G. Mass spectrometer}

The hexapole ion guide where evaporation takes place is part of a commercial Q-TOF Ultima mass spectrometer from Micromass (Waters). This machine consists also of a quadrupole mass filter that can be used to select the ions to enter yet another differentially pumped RF-hexapole collision cell, as well as an orthogonalextraction reflectron time-of-flight mass spectrometer. A microchannel plate (MCP) was used for ion detection. All mass spectra presented in Sec. III were obtained utilizing this instrument (Fig. 5).

\section{PERFORMANCE OF THE INSTRUMENT}

\section{A. Size distributions of charged undoped He nanodroplets}

Mass or size per charge distributions of charged droplet beams are measured by scanning the voltages applied to the rods of the quadrupole bender. The yield of charged droplets is measured with the SEM detector opposite to the pickup cells and TOF-MS (see Fig. 2). Figure 6 shows three distributions measured under identical ion source conditions at three different temperatures of the $\mathrm{He}$ droplet source.

By measuring size per charge distributions for a wide range of source temperatures $(4.4 \mathrm{~K}-12 \mathrm{~K})$ and electron ionization conditions (electron energy from $0 \mathrm{eV}$ to $300 \mathrm{eV}$ and electron current from $1 \mu \mathrm{A}$ to $2 \mathrm{~mA}$ ), we have information on the charged helium droplets before they pass through the pickup cells. At a temperature of $5.4 \mathrm{~K}$, Gomez et al. determined via titration an average droplet size of $1.68 \times 10^{10} \mathrm{He}$ atoms. ${ }^{57}$ Based on an extrapolation of the values taken in Ref. 57, we can expect that the average size of neutral droplets formed at $4.4 \mathrm{~K}$ is larger than $10^{12} \mathrm{He}$ atoms. The kinetic energy of such a droplet flying with approximately $163 \mathrm{~m} / \mathrm{s}^{60}$ exceeds $100 \mathrm{MeV}$. With the highest voltages that can be applied to the quadrupole bender, the maximum number of $\mathrm{He}$ atoms per charge $\left(\# \mathrm{He} / \mathrm{z}\right.$ ) that can be deflected by $90^{\circ}$ is $3.3 \times 10^{7}$. This indicates that the present apparatus can sample HNDs with average charge states exceeding several $10^{4}$ when the droplet source is operated at $4.4 \mathrm{~K}$.

The evaporation of HNDs via collisions with stagnant He gas in the RF-hexapole is limited, and thus, dopant cluster ions can be extracted from HNDs up to a size of about $10^{7}$. The three temperatures used in Fig. 6 cover the optimum range for measuring dopant cluster ions at the TOF mass spectrometer. According to Gomez et al., ${ }^{57}$ the average size of HNDs is $2 \times 10^{6}$ at $9 \mathrm{~K}, 5 \times 10^{6}$ at $8 \mathrm{~K}$,

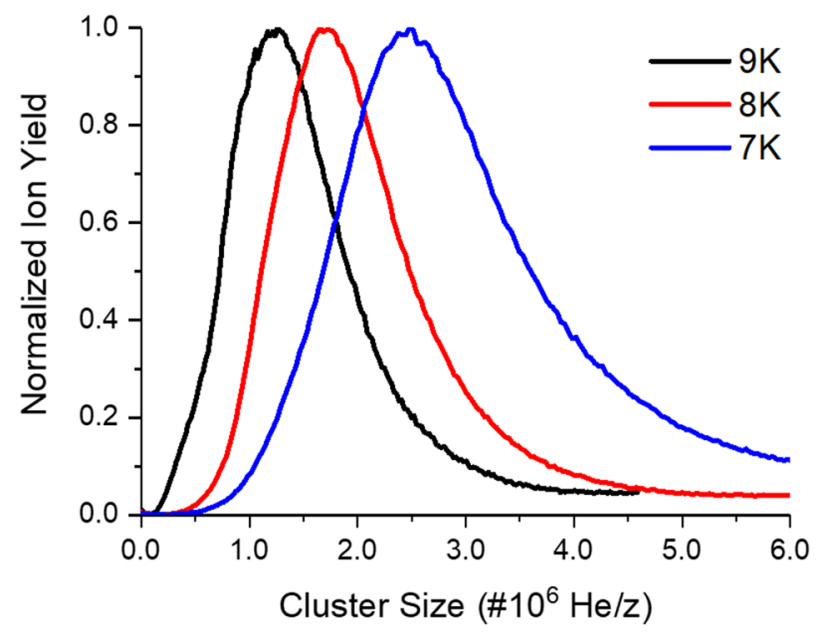

FIG. 6. Ion yield of the nanodroplet beam recorded on the SEM detector as a function of size per charge ratio (number of He atoms divided by the charge state $z)$, for three different nozzle temperatures. The x-axis was calibrated using the linear dependence between quadrupole voltage and kinetic energy determined from Fig. 4(b), and the relationship between temperature and cluster velocity was taken from Refs. 60 and 77 . The electron current used was $300 \mu \mathrm{A}$ at $40 \mathrm{eV}$. 


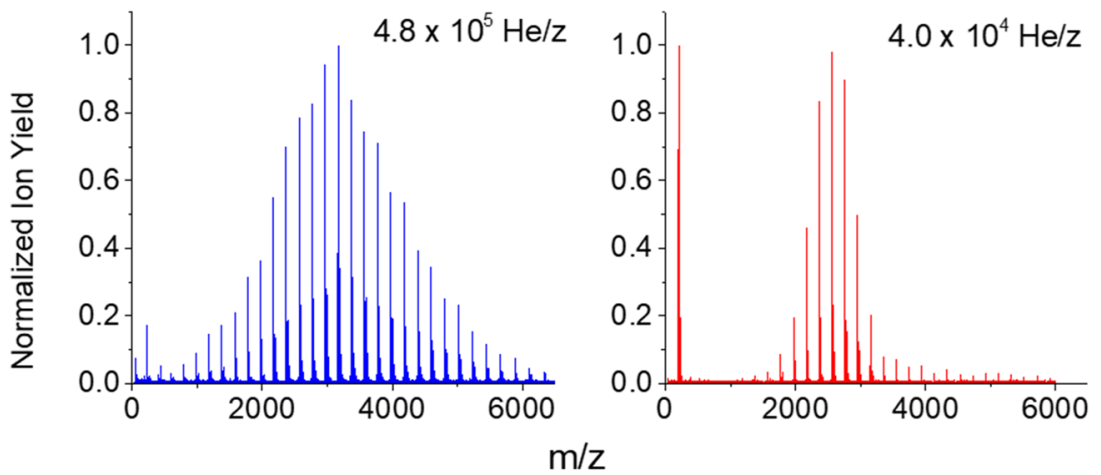

FIG. 7. TOF mass spectra of gold cluster ions formed upon pickup of gold vapor into multiply charged helium droplets for two quadrupole bender configurations. Left panel: oven power of $60 \mathrm{~W}$, He size per charge $=480000$, evaporation cell pressure $=20 \mathrm{mPa}$, and He temperature of $9.2 \mathrm{~K}$; right panel: oven power of 75 $\mathrm{W}$, He size per charge $=40000$, evaporation cell pressure $=10 \mathrm{mPa}$, and $\mathrm{He}$ temperature of $9.6 \mathrm{~K}$ and $10^{7}$ at $7 \mathrm{~K}$. The maximum charge states determined by Laimer et al. ${ }^{68}$ for HNDs of these sizes are 20, 33, and 50, respectively. This is suitable to test our assumptions regarding charge centers acting as seeds for homogeneous multi-center dopant cluster growth.

\section{B. Application example: Gold cluster ions}

Gold is one of our first test samples to produce clusters because, besides its immense importance for cluster science, ${ }^{79-81}$ it is also a material we have a great experience with in experiments where neutral helium droplets are employed, making comparisons between the present technique and our previous apparatus most straightforward. ${ }^{41,82,83}$ Two examples of TOF mass spectra obtained with gold as a dopant in helium droplets are shown in Fig. 7 for two different helium droplet sizes (i.e., mass-per-charge values) selected with the quadrupole bender. In each case, the oven temperature was adjusted in order to obtain similar average dopant cluster sizes. In the left part of Fig. 7, we have selected helium droplet sizes roughly one order of magnitude bigger than those in the right. In the left, we can clearly see the regular pattern of gold clusters with a maximum close to mass 3000 , corresponding to 15 or 16 gold atoms. Also, the distribution is roughly normal and not log-normal as has always been the case in previous experiments. In the right, the distribution is centered at 13 gold atoms, and the width of the distribution is considerably reduced.

In Fig. 8(a), size distributions of gold cluster ions are shown for four different configurations of our quadrupole bender, which correspond to different size per charge values of the helium droplets a)

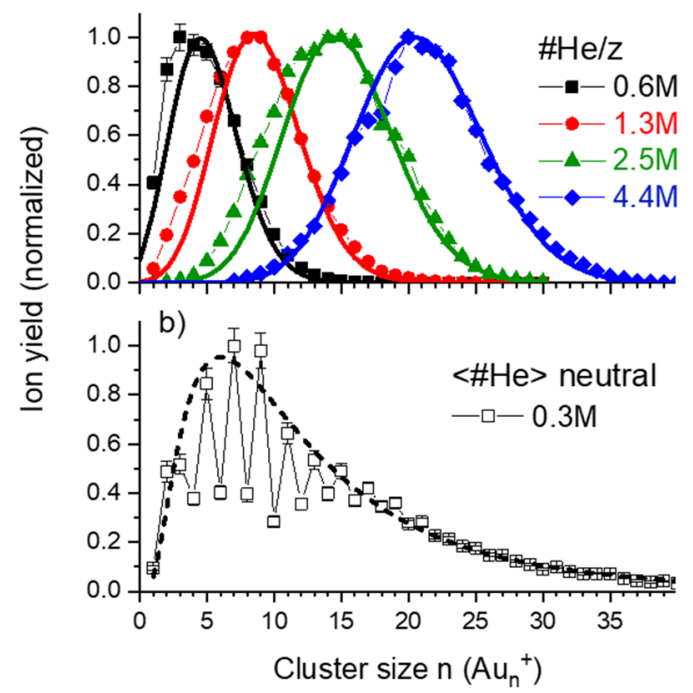

c)

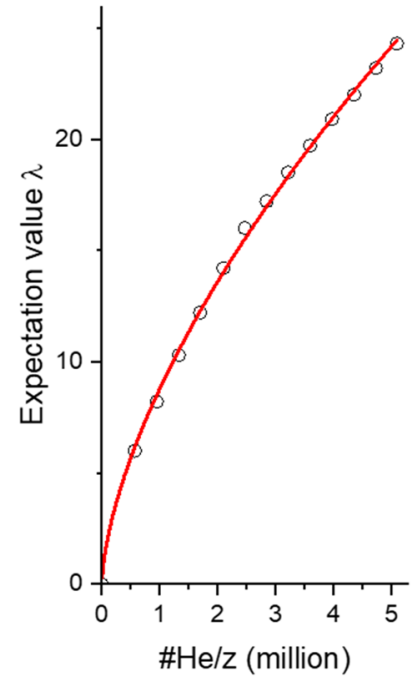

FIG. 8. (a) Normalized ion yield distributions of gold cluster cations formed upon pickup of gold vapor into charged helium droplets of different size per charge ratios, selected by the quadrupole bender. The helium source temperature is $8.5 \mathrm{~K}$, the electron current is $200 \mu \mathrm{A}$ at an electron energy of $62 \mathrm{eV}$, the power of the gold oven is $100 \mathrm{~W}$, and the pressure of the collision gas $\mathrm{He}$ in the RF-hexapole is $0.18 \mathrm{~Pa}$. The solid lines correspond to Poisson distributions with expectation values of $\lambda=6,10,16$, and 20 for selection of progressively larger droplet sizes, respectively. (b) Normalized yield of $\mathrm{Aun}_{n}^{+}$formed upon electron ionization of neutral helium droplets with an average size of $0.3 \times 10^{6} \mathrm{He}$ atoms, doped with gold vapor (data taken from Ref. 82). The dashed line is a log-normal fit to the data, omitting the local minima up to $n=12$, with its center at $x_{c}=10.8$. (c) Expectation values of Poisson distributions fitted to gold cluster ion size distributions measured with the new instrument as shown in (a). The solid line is an allometric fit of the form $y=a x^{b}$, with $a=8.8$ and $b=0.63$. 
prior to pickup, while keeping all other conditions constant. The clusters shown in Fig. 8 are singly charged, but the droplets used to produce the gold clusters were multiply charged. The solid lines correspond to Poisson fits to the data, and the expectation values for those fits are presented in Fig. 8(c). It is very clear that as the quadrupole bender selects bigger size per charge values of the helium droplets, higher expectation values are observed for the number of gold atoms in the clusters. We also observe that a power law fits very well to the data of Fig. 8(c), resulting in an exponent approximately equal to $2 / 3$. This value is consistent with a pickup probability that scales with the geometrical cross section of spherical, singly charged HNDs, even though multiply charge droplets are expected to pass through the analyzer for the $\mathrm{m} / \mathrm{z}$ settings selected.

In order to interpret those observations, we recall that when a multiply charged helium droplet collides with gold vapor, the first captured gold atoms will be attracted by the charge centers, i.e., tightly bound $\mathrm{He}_{3}{ }^{+}$cores surrounded by a dense layer of $\mathrm{He}$ atoms, ${ }^{84}$ often referred to as Atkins snowballs. ${ }^{85}$ The gold atom will be ionized via charge transfer as the ionization energy of an Atkins snowball is higher than the ionization energy of the gold atom. The presence of more than one charge in a helium droplet leads to minimum energy configurations in the form of Coulomb crystals ${ }^{68}$ with uniform separation of the charge centers. As each charge center will act as a competing seed for cluster growth, larger droplets that contain more charges will distribute the captured dopants into more dopant clusters. The maximum charge density of a multiply charged HND is determined by the surface tension. Thus, the minimal distance between charge centers can be expected to be almost constant and the maximum number of charges in a droplet is proportional to the surface of HNDs. As the pickup cross section exhibits the same dependence on the droplet size as the maximum number of charges, the ratio of total dopants captured and the dopant charge state is a constant for all droplet sizes. This explains the observed reduction in the size distribution of dopant cluster ions compared to existing techniques.

Observing Fig. 8(a) more closely, we see that experimental values for the gold cluster sizes deviate slightly from the Poisson fits. Except for the measurement with charged helium droplets consisting of $4.4 \times 10^{6}$ atoms per charge (solid diamonds), the data points left of the maximum of the distribution are clearly larger than the Poisson fit. This can be explained by the fact that for small HNDs, the amount of helium atoms lost due to evaporation after each pickup event is not negligible anymore and the pickup self-terminates, distorting the distribution.

For comparison, in Fig. 8(b), we show data from a previous study ${ }^{82}$ for the size distribution of cationic gold clusters measured upon electron ionization of neutral helium droplets, of average size $0.3 \times 10^{6} \mathrm{He}$ atoms, doped with gold atoms. The dashed line represents a log-normal fit to the data, omitting the local minima up to $n=12$. Besides a more narrow size distribution for gold cluster ions grown in the charged helium droplets, the data in the upper diagram are also lacking an oddeven oscillation and a shell closure at $\mathrm{n}=9$. As every gold atom attaching to a charged cluster can release its binding energy into the He matrix, one would not expect magic number clusters to exhibit enhanced intensity compared to their neighboring cluster sizes.
In the present experiment, helium surrounding the ions is removed by multiple collisions in an RF-hexapole filled with $\mathrm{He}$, and depending on the chosen pressure and collision energy, it is possible to liberate cluster ions with a few helium atoms still attached, as shown in Fig. 9. The lower graph shows a mass spectrum measured with a conventional instrument where neutral droplets with an average size of $10^{6} \mathrm{He}$ atoms are doped with gold and only then ionized by electron impact. The total ion yield of pure gold clusters obtained with the new instrument is more than two orders of magnitude higher than with the old setup and for He-tagged gold cluster ions; this factor increases up to 5000 . The observation that this setup permits a controlled production of He-tagged clusters can be of major interest in the field of ion spectroscopy, especially at low temperatures. ${ }^{86-100}$

\section{Application example: Fullerenes}

Using the same oven as in the gold case, we vaporized fullerenes that were picked up by size per charge selected HNDs. The upper diagram of Fig. 10 shows three sections of a mass spectrum where the conditions were set to obtain fullerene cluster ions with a few $\mathrm{He}$ atoms attached. The maximum yield of helium tagged $\mathrm{C}_{60}$ by electron ionization of neutral HNDs doped with $\mathrm{C}_{60}$ was below $1 \%$ of the yield of the bare ion, as shown by the light-colored line that is multiplied with a factor of 500 in Fig. 10. It has to be mentioned that the measurement shown in the lower diagram of Fig. 10 exhibits the highest relative yield of He-tagged fullerenes from several hundred mass spectra taken. In both experiments, the attachment of at least one water molecule can be seen. With the new

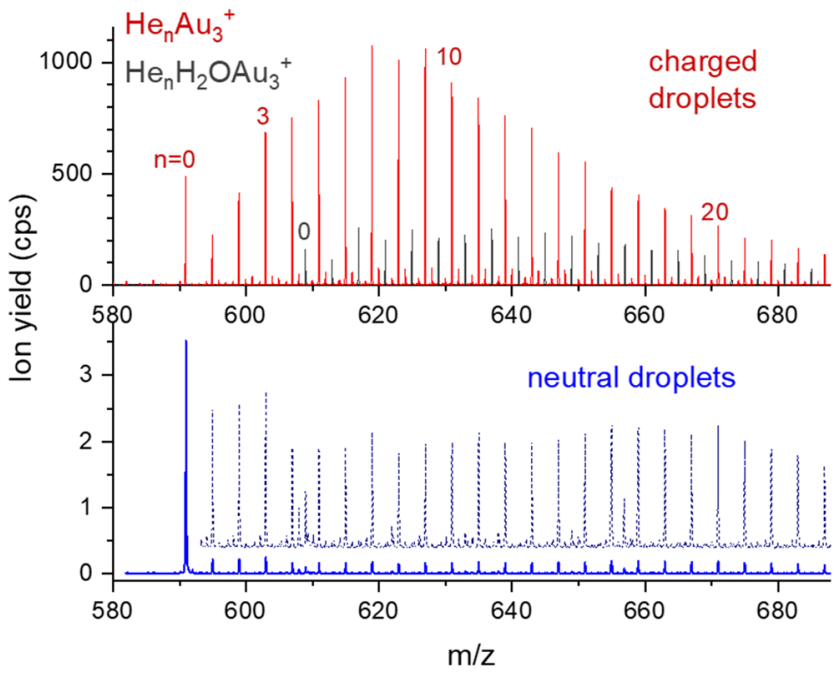

FIG. 9. Section of two mass spectra in the range of $\mathrm{Au}_{3}{ }^{+}$. The upper spectrum was obtained upon passing charged helium droplets $\left(\# \mathrm{He} / \mathrm{z}=0.4 \mathrm{M}, \mathrm{T}_{\mathrm{He}}=9 \mathrm{~K}, \mathrm{I}_{\mathrm{el}}=\right.$ $330 \mu \mathrm{A}, \mathrm{E}_{\mathrm{el}}=71 \mathrm{eV}$ ) through gold vapor produced in an oven heated at $130 \mathrm{~W}$ and colliding the charged and doped HNDs with $\mathrm{He}$ filled at $11 \mathrm{mPa}$ into an RFhexapole. Besides $\mathrm{Au}_{3}{ }^{+}$pronounced peaks of $\mathrm{He}_{n} \mathrm{Au}_{3}{ }^{+}$and $\mathrm{He}_{n}\left(\mathrm{H}_{2} \mathrm{O}\right) \mathrm{Au}_{3}{ }^{+}$can be seen with a similar yield. The lower mass spectrum was obtained upon electron ionization of neutral gold doped HNDs (conditions: $9.4 \mathrm{~K}, 2.25 \mathrm{MPa}$, $\langle \# \mathrm{He}\rangle \sim 1 \mathrm{M}$, $110 \mu \mathrm{A}, 48 \mathrm{eV}, \mathrm{T}_{\mathrm{Au}}=1300 \mathrm{~K}$, and $104 \mathrm{~W}$ ). The dashed line is the same spectrum but multiplied by a factor of 10 . 


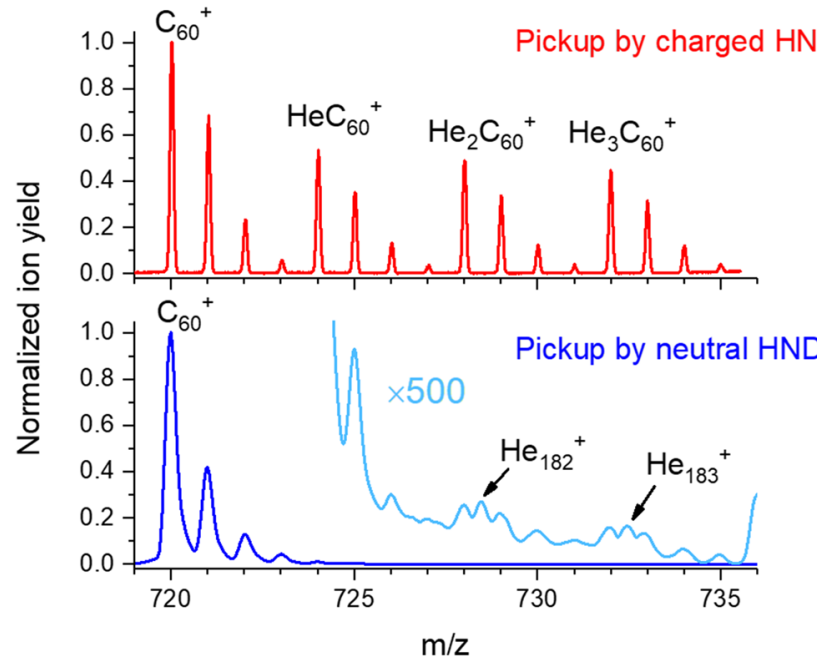

FIG. 10. Section of two mass spectra in the range of $\mathrm{C}_{60}{ }^{+}$. The upper spectrum was obtained upon passing charged helium droplets (\#He/z $=0.7 \mathrm{M}, \mathrm{T}_{\mathrm{He}}=9 \mathrm{~K}, \mathrm{l}_{\mathrm{el}}$ $=400 \mu \mathrm{A}$, and $\mathrm{E}_{\mathrm{e}}=70 \mathrm{eV}$ ) through a fullerene vapor produced in an oven heated at $6 \mathrm{~W}$ and colliding the charged and doped HNDs with $\mathrm{He}$ filled at $24 \mathrm{mPa}$ into an RF-hexapole. Besides $\mathrm{C}_{60}{ }^{+}$pronounced peaks of $\mathrm{He}_{n} \mathrm{C}_{60}{ }^{+}$can be seen with a similar yield. The lower mass spectrum was obtained upon electron ionization of neutral HNDs doped with $\mathrm{C}_{60}$ [conditions: $9.5 \mathrm{~K}, 2 \mathrm{MPa},\langle \# \mathrm{He}\rangle \sim 0.5 \mathrm{M}, 66 \mu \mathrm{A}$, $80 \mathrm{eV}$, and $\left.\mathrm{T}\left(\mathrm{C}_{60}\right)=593 \mathrm{~K}\right]$. The peak between the first and second isotopologues of $\mathrm{He}_{n} \mathrm{C}_{60}{ }^{+}$can be assigned to $\mathrm{He}_{180+n}+.92$

instrument, the yield of helium tagged fullerene ions is about three orders of magnitude higher, which is extremely beneficial for action spectroscopy.

\section{Application example: Water}

In Fig. 11, three mass spectra of charged helium droplets doped with water are shown. Water was added as an impurity to the collision gas introduced into the RF-hexapole, as explained above. At low pressure, the dominant ion series is $\mathrm{He}_{\mathrm{n}}\left(\mathrm{H}_{2} \mathrm{O}\right)_{\mathrm{m}}{ }^{+}$with the water content of each helium n-mer following roughly a log-normal distribution. Protonated water clusters are less intense than the stoichiometric ion series and are hardly solvated with He. With increasing collision gas pressure, also the stoichiometric water cluster ions are exempted from attached $\mathrm{He}$, the protonated ions become more abundant and the center of the log-normal size distribution of water cluster ions shrinks from $\mathrm{m}=4.3$ to 4.1 and 3.9. At the present stage, it is not clear whether $\left(\mathrm{H}_{2} \mathrm{O}\right)_{\mathrm{m}}{ }^{+}$clusters are in fact protonated cluster ions with an $\mathrm{OH}$ fragment attached that is removed upon collisional activation or the proton transfer reaction requires an activation energy.

\section{E. Application example: Serine}

Figure 12 shows a comparison of cluster ions formed upon pickup of serine into size per charge selected HND (parameters will be introduced) and neutral $\mathrm{HND}\left(\mathrm{T}_{\mathrm{He}}=9.7 \mathrm{~K}, \mathrm{p}_{\mathrm{He}}=2.5 \mathrm{MPa}, \mathrm{I}_{\mathrm{el}}\right.$ $=103 \mu \mathrm{A}, \mathrm{E}_{\mathrm{el}}=78 \mathrm{eV}$, and $\left.\mathrm{T}_{\text {serine }}=386 \mathrm{~K}\right)$. The He pressure in the RF-hexapole was high enough to liberate all serine cluster ions from

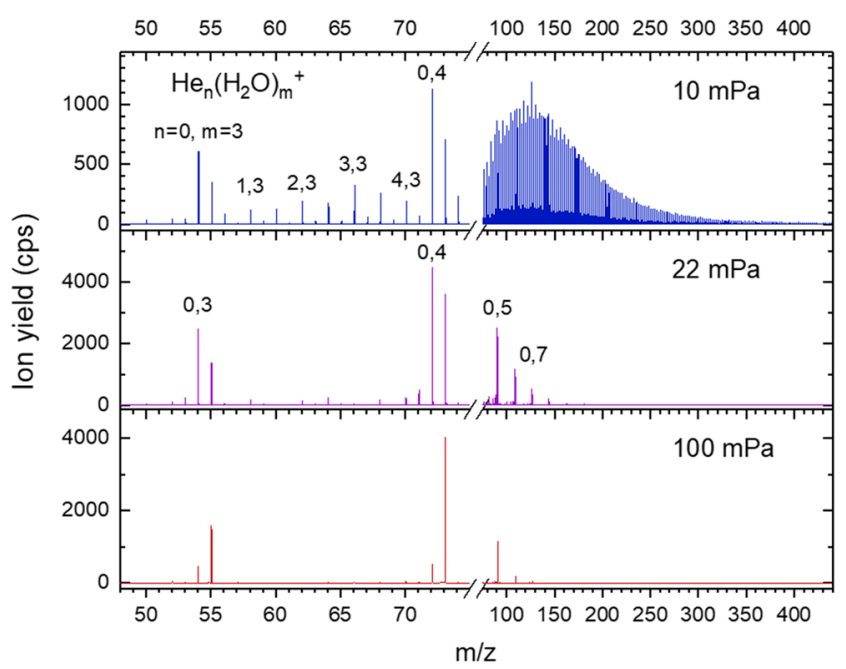

FIG. 11. Mass spectra of charged helium droplets doped with water $(\# H e / z=3 M$ $\mathrm{T}_{\mathrm{He}}=8.2 \mathrm{~K}$, $\mathrm{I}_{\mathrm{el}}=350 \mu \mathrm{A}$, and $\left.\mathrm{E}_{\mathrm{el}}=70 \mathrm{eV}\right)$. A small amount $(<0.01 \%)$ of water was added to $\mathrm{He}$ as a collision gas and introduced at three different pressures into the RF-hexapole. At $10 \mathrm{mPa}$ collision gas pressure, most water cluster ions are solvated with several $\mathrm{He}$ atoms. The dominant ion series is $\mathrm{He}_{n}\left(\mathrm{H}_{2} \mathrm{O}\right)_{\mathrm{m}}{ }^{+}$and not protonated water clusters. With an increase in the collision gas pressure, large water cluster ions have lost all attached $\mathrm{He}$ atoms and the protonated water cluster ions become more abundant.

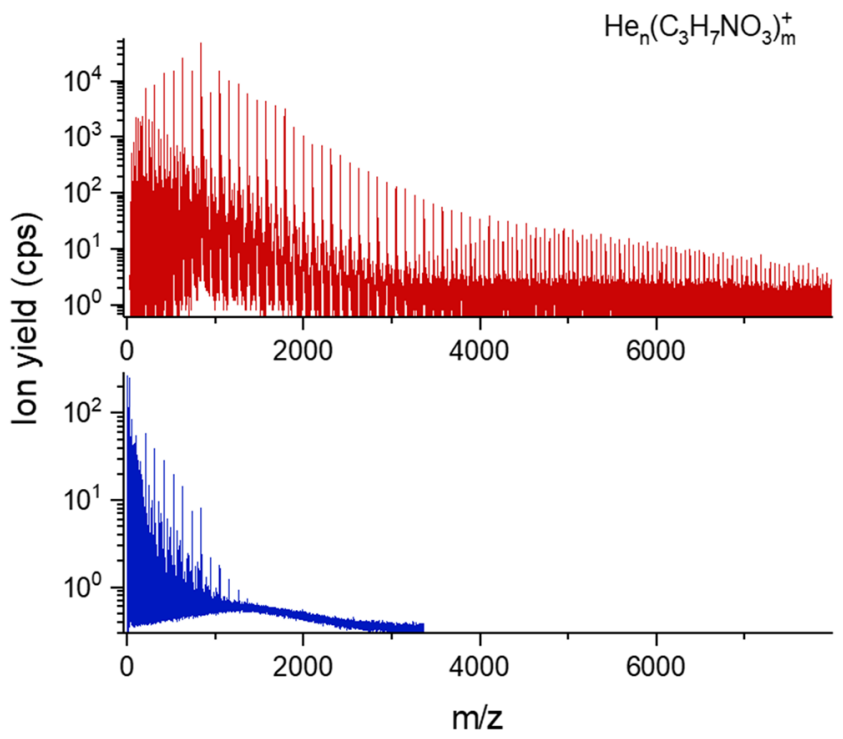

FIG. 12. Mass spectra of charged helium droplets doped with serine (\#He/z $=5.3 \mathrm{M}, \mathrm{T}_{\mathrm{He}}=8 \mathrm{~K}, \mathrm{l}_{\mathrm{el}}=410 \mu \mathrm{A}$, and $\left.\mathrm{E}_{\mathrm{el}}=37.3 \mathrm{eV}\right)$. The conditions were optimized for large serine cluster ions. The He pressure in the RF-hexapole was high enough to remove all $\mathrm{He}$ atoms attached to the cluster ions. Under these conditions, the protonated serine cluster ions are prevalent and the magic serine octamer can be seen as the strongest peak. The lower diagram shows a mass spectrum of cations formed upon electron ionization of serine doped HNDs $\left(T_{\mathrm{He}}=9.7 \mathrm{~K}\right.$, $\mathrm{P}_{\mathrm{He}}=2.5 \mathrm{MPa}, \mathrm{I}_{\mathrm{el}}=103 \mu \mathrm{A}, \mathrm{E}_{\mathrm{el}}=78 \mathrm{eV}$, and $\mathrm{T}_{\text {serine }}=386 \mathrm{~K}$ ). 
excess $\mathrm{He}$ and collision induced activation led to an enhancement of protonated cluster ions and a pronounced magic number at the serine octamer, just as in the case of electron ionization of serine doped neutral HNDs. The magic serine octamer has been described extensively in the literature. ${ }^{101-103}$ Beyond $n=30$, a series of peaks in the middle between two serine cluster ions appears and can be assigned to doubly charged serine cluster ions.

\section{SUMMARY AND CONCLUSIONS}

A versatile method for the production of intense beams of charged clusters and nanoparticles with a narrow size distribution has been demonstrated. Compared to the state of the art, the presented instrument ionizes the helium droplets prior to the "pickup" of vapor agglomerating into neutral clusters. A direct consequence of this new arrangement was that every charge center will act as a seed for dopant cluster growth. In the case of multiply charged HNDs, many singly charged dopant clusters are formed in parallel. By using a collision chamber and an RF ion guide, it was possible to extract the clusters from the helium droplets, making them accessible for mass spectrometry. Depending on the pressure of the collision gas in the RF ion guide, dopant cluster ions with only few helium atoms can be formed. The possibility to form intense beams of complex ions that are solvated with any desired number of $\mathrm{He}$ atoms offers new avenues for messenger type and matrix isolation spectroscopy. ${ }^{86-93}$ Clusters of biomolecules can be microsolvated with water which is an important issue to simulate life-like conditions and difficult to achieve with other methods. ${ }^{104-107}$

\section{ACKNOWLEDGMENTS}

This work was supported by EFRE (K-Regio project FAENOMENAL, Grant No. EFRE 2016-4) and the Austrian Science Fund FWF (Project No. P31149, I4130). This work was also supported by Fundação para a Ciência e a Tecnologia (FCT-MCTES), Radiation Biology and Biophysics Doctoral Training Programme (RaBBiT, PD/00193/2012); Applied Molecular Biosciences Unit - UCIBIO (UIDB/04378/2020) and CEFITEC Unit (UIDB/00068/2020); and scholarship Grant No. PD/BD/114447/2016 to J.A., F. Zappa acknowledges support from the Brazilian agency CNPq. K.v.H. kindly acknowledges the award of a LFUI guest professorship.

\section{REFERENCES}

${ }^{1}$ W. D. Knight, K. Clemenger, W. A. Deheer, W. A. Saunders, M. Y. Chou, and M. L. Cohen, Phys. Rev. Lett. 52(24), 2141-2143 (1984).

${ }^{2}$ H. Hakkinen, B. Yoon, U. Landman, X. Li, H. J. Zhai, and L. S. Wang, J. Phys. Chem. A 107(32), 6168-6175 (2003).

${ }^{3}$ U. Heiz, A. Sanchez, S. Abbet, and W. D. Schneider, J. Am. Chem. Soc. 121(13), 3214-3217 (1999).

${ }^{4}$ A. W. Castleman and S. N. Khanna, J. Phys. Chem. C 113(7), 2664-2675 (2009).

${ }^{5}$ E. C. Tyo and S. Vajda, Nat. Nanotechnol. 10(7), 577-588 (2015).

${ }^{6}$ D. C. Lim, C. C. Hwang, G. Gantefor, and Y. D. Kim, Phys. Chem. Chem. Phys. 12(46), 15172-15180 (2010).

${ }^{7}$ B. Yoon, P. Koskinen, B. Huber, O. Kostko, B. von Issendorff, H. Hakkinen, M. Moseler, and U. Landman, ChemPhysChem 8(1), 157-161 (2007).

${ }^{8}$ G. E. Johnson, T. Moser, M. Engelhard, N. D. Browning, and J. Laskin, J. Chem, Phys. 145(17), 174701 (2016).
${ }^{9}$ N. Jian, K. Bauer, and R. E. Palmer, Nanotechnology 28(32), 325601 (2017).

${ }^{10}$ R. E. Palmer, R. S. Cai, and J. Vernieres, Acc. Chem. Res. 51(9), 2296-2304 (2018).

${ }^{11}$ J. Laskin, G. E. Johnson, and V. Prabhakaran, J. Phys. Chem. C 120(41), 23305 (2016).

${ }^{12}$ M.-C. Daniel and D. Astruc, Chem. Rev. 104(1), 293-346 (2004).

${ }^{13}$ A. Akraiam and K. von Haeften, Eur. Phys. J. D 67(4), 86 (2013).

${ }^{14}$ M. J. McNally, G. Galinis, O. Youle, M. Petr, R. Prucek, L. Machala, and K. von Haeften, Nanoscale Adv. 1(10), 4041-4051 (2019).

${ }^{15}$ M. Brust, M. Walker, D. Bethell, D. J. Schiffrin, and R. Whyman, J. Chem. Soc.: Chem. Commun. 1994(7), 801-802.

${ }^{16}$ I. Katakuse, T. Ichihara, Y. Fujita, T. Matsuo, T. Sakurai, and H. Matsuda, Int. J. Mass Spectrom. Ion Processes 67(2), 229-236 (1985).

${ }^{17}$ E. Limpert, M. Abbt, and W. A. Stahel, BioScience 51(5), 341-352 (2001).

${ }^{18}$ M. F. Jarrold and V. A. Constant, Phys. Rev. Lett. 67(21), 2994-2997 (1991).

${ }^{19}$ U. Buck and F. Huisken, Chem. Rev. 100(11), 3863-3890 (2000).

${ }^{20} \mathrm{M}$. Schmidt, R. Kusche, B. von Issendorff, and H. Haberland, Nature 393(6682), 238-240 (1998).

${ }^{21}$ G. von Helden, M. T. Hsu, N. Gotts, and M. T. Bowers, J. Phys. Chem. 97(31), 8182-8192 (1993).

${ }^{22}$ W. K. Lewis, B. A. Harruff-Miller, P. Leatherman, M. A. Gord, and C. E. Bunker, Rev. Sci. Instrum. 85(9), 094102 (2014).

${ }^{23}$ P. Fayet and L. Wöste, Surf. Sci. 156, 134-139 (1985).

${ }^{24}$ H. R. Siekmann, C. Luder, J. Faehrmann, H. O. Lutz, and K. H. Meiwesbroer, Z. Phys. D: At., Mol. Clusters 20(1-4), 417-420 (1991).

${ }^{25}$ H. Haberland, M. Karrais, M. Mall, and Y. Thurner, J. Vac. Sci. Technol., A 10(5), 3266-3271 (1992).

${ }^{26}$ S. Pratontep, S. J. Carroll, C. Xirouchaki, M. Streun, and R. E. Palmer, Rev. Sci. Instrum. 76(4), 045103 (2005).

${ }^{27}$ H. Haberland, Z. Insepov, and M. Moseler, Phys. Rev. B 51(16), 11061-11067 (1995).

${ }^{28}$ C. Yin, E. Tyo, K. Kuchta, B. von Issendorff, and S. Vajda, J. Chem. Phys. 140(17), 174201 (2014).

${ }^{29}$ G. E. Johnson, R. Colby, and J. Laskin, Nanoscale 7(8), 3491-3503 (2015).

${ }^{30}$ L. Martinez, K. Lauwaet, G. Santoro, J. M. Sobrado, R. J. Pelaez, V. J. Herrero, I. Tanarro, G. J. Ellis, J. Cernicharo, C. Joblin, Y. Huttel, and J. A. Martin-Gago, Sci. Rep. 8, 7250 (2018).

${ }^{31}$ C. H. Zhang, H. Tsunoyama, H. Akatsuka, H. Sekiya, T. Nagase, and A. Nakajima, J. Phys. Chem. A 117(40), 10211-10217 (2013).

${ }^{32}$ T. G. Dietz, M. A. Duncan, D. E. Powers, and R. E. Smalley, J. Chem. Phys. 74(11), 6511-6512 (1981).

${ }^{33}$ T. E. Gough, M. Mengel, P. A. Rowntree, and G. Scoles, J. Chem. Phys. 83(10), 4958-4961 (1985).

${ }^{34}$ M. Lewerenz, B. Schilling, and J. P. Toennies, J. Chem. Phys. 102(20), 8191-8207 (1995).

${ }^{35}$ A. Mauracher, O. Echt, A. M. Ellis, S. Yang, D. K. Bohme, J. Postler, A. Kaiser, S. Denifl, and P. Scheier, Phys. Rep.: Rev. Sec. Phys. Lett. 751, 1-90 (2018).

${ }^{36}$ J. P. Toennies and A. F. Vilesov, Angew. Chem., Int. Ed. 43(20), 2622-2648 (2004).

${ }^{37}$ L. G. Mendoza-Luna, N. M. K. Shiltagh, M. J. Watkins, N. Bonifaci, F. Aitken, and K. von Haeften, J. Phys. Chem. Lett. 7(22), 4666-4670 (2016).

${ }^{38}$ A. Boatwright, C. Feng, D. Spence, E. Latimer, C. Binns, A. M. Ellis, and S. F. Yang, Faraday Discuss. 162, 113-124 (2013).

${ }^{39}$ G. Haberfehlner, P. Thaler, D. Knez, A. Volk, F. Hofer, W. E. Ernst, and G. Kothleitner, Nat. Commun. 6, 8779 (2015).

${ }^{40}$ S. Denifl, F. Zappa, I. Maehr, F. F. da Silva, A. Aleem, A. Mauracher, M. Probst, J. Urban, P. Mach, A. Bacher, O. Echt, T. D. Maerk, and P. Scheier, Angew. Chem., Int. Ed. 48(47), 8940-8943 (2009).

${ }^{41}$ M. Goulart, M. Kuhn, P. Martini, L. Chen, F. Hagelberg, A. Kaiser, P. Scheier, and A. M. Ellis, J. Phys. Chem. Lett. 9(10), 2703-2706 (2018).

${ }^{42}$ L. Kranabetter, M. Goulart, A. Aleem, T. Kurzthaler, M. Kuhn, E. Barwa, M. Renzler, L. Grubwieser, M. Schwärzler, A. Kaiser, P. Scheier, and O. Echt, J. Phys. Chem. C 121(20), 10887-10892 (2017). 
${ }^{43}$ A. Kaiser, S. Zoettl, P. Bartl, C. Leidlmair, A. Mauracher, M. Probst, S. Denifl, O. Echt, and P. Scheier, Chemsuschem 6(7), 1235-1244 (2013).

${ }^{44}$ R. E. Palmer, L. Cao, and F. Yin, Rev. Sci. Instrum. 87(4), 046103 (2016).

${ }^{45}$ Z. Y. Li, N. P. Young, M. Di Vece, S. Palomba, R. E. Palmer, A. L. Bleloch, B. C. Curley, R. L. Johnston, J. Jiang, and J. Yuan, Nature 451(7174), 46-48 (2008).

${ }^{46}$ E. W. Becker, R. Klingelhöfer, and P. Lohse, Z. Naturforsch. A 16, 1259 (1961).

${ }^{47}$ E. W. Becker, R. Klingelhöfer, and P. Lohse, Z. Naturforsch. A 17, 432 (1962).

${ }^{48}$ J. Gspann, Surf. Sci. 106(1), 219-224 (1981).

${ }^{49}$ S. Kuma and T. Azuma, Cryogenics 88, 78-80 (2017).

${ }^{50}$ R. Katzy, M. Singer, S. Izadnia, A. C. LaForge, and F. Stienkemeier, Rev. Sci. Instrum. 87(1), 013105 (2016).

${ }^{51}$ D. Pentlehner, R. Riechers, B. Dick, A. Slenczka, U. Even, N. Lavie, R. Brown, and K. Luria, Rev. Sci. Instrum. 80(4), 043302 (2009).

${ }^{52}$ L. Chen, J. Zhang, W. M. Freund, and W. Kong, J. Chem. Phys. 143(4), 044310 (2015).

${ }^{53}$ M. Ratschek, M. Koch, and W. E. Ernst, J. Chem. Phys. 136(10), 104201 (2012).

${ }^{54}$ M. Koch, J. Lanzersdorfer, C. Callegari, J. S. Muenter, and W. E. Ernst, J. Phys. Chem. A 113(47), 13347-13356 (2009).

${ }^{55} \mathrm{M}$. N. Slipchenko, S. Kuma, T. Momose, and A. F. Vilesov, Rev. Sci. Instrum. 73(10), 3600-3605 (2002)

${ }^{56}$ D. Verma and A. F. Vilesov, Chem. Phys. Lett. 694, 129-134 (2018).

${ }^{57}$ L. F. Gomez, E. Loginov, R. Sliter, and A. F. Vilesov, J. Chem. Phys. 135(15), 154201 (2011)

${ }^{58}$ H. Buchenau, E. L. Knuth, J. Northby, J. P. Toennies, and C. Winkler, J. Chem. Phys. 92(11), 6875-6889 (1990).

${ }^{59}$ R. Sliter, L. F. Gomez, J. Kwok, and A. Vilesov, Chem. Phys. Lett. 600, 29-33 (2014).

${ }^{60} \mathrm{U}$. Henne and J. P. Toennies, J. Chem. Phys. 108(22), 9327-9338 (1998).

${ }^{61}$ Y. Dong and M. Springborg, J. Phys. Chem. C 111(34), 12528-12535 (2007).

${ }^{62}$ C. Bernando, R. M. P. Tanyag, C. Jones, C. Bacellar, M. Bucher, K. R. Ferguson, D. Rupp, M. P. Ziemkiewicz, L. F. Gomez, A. S. Chatterley, T. Gorkhover, M. Müller, J. Bozek, S. Carron, J. Kwok, S. L. Butler, T. Möller, C. Bostedt, O. Gessner, and A. F. Vilesov, Phys. Rev. B 95(6), 064510 (2017).

${ }^{63}$ D. Rupp, N. Monserud, B. Langbehn, M. Sauppe, J. Zimmermann, Y. Ovcharenko, T. Möller, F. Frassetto, L. Poletto, A. Trabattoni, F. Calegari, M. Nisoli, K. Sander, C. Peltz, M. J. Vrakking, T. Fennel, and A. Rouzée, Nat. Commun. 8(1), 493 (2017).

${ }^{64}$ L. F. Gomez, K. R. Ferguson, J. P. Cryan, C. Bacellar, R. M. P. Tanyag, C. Jones, S. Schorb, D. Anielski, A. Belkacem, C. Bernando, R. Boll, J. Bozek, S. Carron, G. Chen, T. Delmas, L. Englert, S. W. Epp, B. Erk, L. Foucar, R. Hartmann, A. Hexemer, M. Huth, J. Kwok, S. R. Leone, J. H. S. Ma, F. Maia, E. Malmerberg, S. Marchesini, D. M. Neumark, B. Poon, J. Prell, D. Rolles, B. Rudek, A. Rudenko, M. Seifrid, K. R. Siefermann, F. P. Sturm, M. Swiggers, J. Ullrich, F. Weise, P. Zwart, C. Bostedt, O. Gessner, and A. F. Vilesov, Science 345(6199), 906-909 (2014).

${ }^{65}$ A. M. Ellis and S. F. Yang, Phys. Rev. A 76(3), 032714 (2007).

${ }^{66}$ W. K. Lewis, C. M. Lindsay, R. J. Bemish, and R. E. Miller, J. Am. Chem. Soc. 127(19), 7235-7242 (2005).

${ }^{67}$ S. Vongehr, A. A. Scheidemann, C. Wittig, and V. V. Kresin, Chem. Phys. Lett. 353(1), 89-94 (2002).

${ }^{68}$ F. Laimer, L. Kranabetter, L. Tiefenthaler, S. Albertini, F. Zappa, A. M. Ellis, M. Gatchell, and P. Scheier, Phys. Rev. Lett. 123(16), 165301 (2019).

${ }^{69}$ I. V. Krasnov and L. P. Kamenshchikov, Laser Phys. 28(10), 105701 (2018).

${ }^{70} \mathrm{~S}$. Willitsch, M. T. Bell, A. D. Gingell, S. R. Procter, and T. P. Softley, Phys. Rev. Lett. 100(4), 043203 (2008).

${ }^{71}$ Y.-P. Chang, K. Długołęcki, J. Küpper, D. Rösch, D. Wild, and S. Willitsch, Science 342(6154), 98-101 (2013).

${ }^{72}$ A. Mauracher, M. Daxner, J. Postler, S. E. Huber, S. Denifl, P. Scheier, and J. P. Toennies, J. Phys. Chem. Lett. 5(14), 2444-2449 (2014).

${ }^{73}$ F. Zappa, S. Denifl, I. Maehr, A. Bacher, O. Echt, T. D. Maerk, and P. Scheier, J. Am. Chem. Soc. 130(16), 5573-5578 (2008).
${ }^{74}$ E. Jabbour Al Maalouf, J. Reitshammer, A. Ribar, P. Scheier, and S. Denifl, Eur. Phys. J. D 70(7), 148 (2016).

${ }^{75}$ J. P. Toennies and K. Winkelmann, J. Chem. Phys. 66(9), 3965-3979 (1977).

${ }^{76}$ R. E. Grisenti and J. P. Toennies, Phys. Rev. Lett. 90(23), 234501 (2003).

${ }^{77}$ M. Fárník, U. Henne, B. Samelin, and J. P. Toennies, Z. Phys. D: At., Mol. Clusters 40(1), 93-98 (1997).

${ }^{78}$ T. Jiang and J. A. Northby, Phys. Rev. Lett. 68(17), 2620-2623 (1992).

${ }^{79}$ D. Astruc, F. Lu, and J. R. Aranzaes, Angew. Chem., Int. Ed. 44(48), 7852-7872 (2005).

${ }^{80}$ M. Haruta, N. Yamada, T. Kobayashi, and S. Iijima, J. Catal. 115(2), 301-309 (1989).

${ }^{81}$ P. Schwerdtfeger, Angew. Chem., Int. Ed. 42(17), 1892-1895 (2003).

${ }^{82}$ P. Martini, L. Kranabetter, M. Goulart, M. Kuhn, M. Gatchell, D. K. Bohme, and P. Scheier, Int. J. Mass Spectrom. 434, 136-141 (2018).

${ }^{83}$ M. Goulart, M. Gatchell, L. Kranabetter, M. Kuhn, P. Martini, N. Gitzl, M. Rainer, J. Postler, P. Scheier, and A. M. Ellis, Phys. Chem. Chem. Phys. 20(14), 9554-9560 (2018).

${ }^{84}$ D. Mateo and J. Eloranta, J. Phys. Chem. A 118(33), 6407-6415 (2014).

${ }^{85}$ K. R. Atkins, Phys. Rev. 116(6), 1339-1343 (1959).

${ }^{86}$ E. J. Bieske and O. Dopfer, Chem. Rev. 100(11), 3963-3998 (2000).

${ }^{87}$ O. Asvany, P. Kumar, B. Redlich, I. Hegemann, S. Schlemmer, and D. Marx, Science 309(5738), 1219-1222 (2005).

${ }^{88}$ O. Asvany, S. Brunken, L. Kluge, and S. Schlemmer, Appl. Phys. B: Lasers Opt. 114(1-2), 203-211 (2014).

${ }^{89}$ J. Roithová, A. Gray, E. Andris, J. Jašík, and D. Gerlich, Acc. Chem. Res. 49(2), 223-230 (2016).

${ }^{90}$ J. Roithova, J. Jasik, J. J. D. Mellado, and D. Gerlich, Faraday Discuss. 217, 98 113 (2019)

${ }^{91}$ M. Gatchell, P. Martini, F. Laimer, M. Goulart, F. Calvo, and P. Scheier, Faraday Discuss. 217, 276-289 (2019).

${ }^{92}$ M. Kuhn, M. Renzler, J. Postler, S. Ralser, S. Spieler, M. Simpson, H. Linnartz, A. G. G. M. Tielens, J. Cami, A. Mauracher, Y. Wang, M. Alcamí, F. Martín, M. K. Beyer, R. Wester, A. Lindinger, and P. Scheier, Nat. Commun. 7(1), 13550 (2016).

${ }^{93}$ F. Uhl and D. Marx, Angew. Chem., Int. Ed. 57(45), 14792-14795 (2018).

${ }^{94}$ E. K. Campbell, M. Holz, D. Gerlich, and J. P. Maier, Nature 523(7560), 322-323 (2015).

${ }^{95}$ D. Gerlich, J. Jašík, D. V. Strelnikov, and J. Roithová, Astrophys. J. 864(1), 62 (2018).

${ }^{96}$ A. Günther, P. Nieto, D. Müller, A. Sheldrick, D. Gerlich, and O. Dopfer, J. Mol. Spectrosc. 332, 8-15 (2017).

${ }^{97}$ V. Scutelnic and T. R. Rizzo, J. Phys. Chem. A 123(13), 2815-2819 (2019).

${ }^{98}$ H. Kohguchi, P. Jusko, K. M. T. Yamada, S. Schlemmer, and O. Asvany, J. Chem. Phys. 148(14), 144303 (2018).

${ }^{99}$ O. Asvany, S. Schlemmer, T. Szidarovszky, and A. G. Csaszar, J. Phys. Chem. Lett. 10(18), 5325-5330 (2019).

${ }^{100}$ A. Kaiser, J. Postler, M. Ončák, M. Kuhn, M. Renzler, S. Spieler, M. Simpson, M. Gatchell, M. K. Beyer, R. Wester, F. A. Gianturco, P. Scheier, F. Calvo, and E. Yurtsever, J. Phys. Chem. Lett. 9(6), 1237-1242 (2018).

${ }^{101}$ R. G. Cooks, D. Zhang, K. J. Koch, F. C. Gozzo, and M. N. Eberlin, Anal. Chem. 73(15), 3646-3655 (2001).

${ }^{102}$ S. C. Nanita and R. G. Cooks, Angew. Chem., Int. Ed. 45(4), 554-569 (2006).

${ }^{103}$ F. Ferreira da Silva, P. Bartl, S. Denifl, T. D. Märk, A. M. Ellis, and P. Scheier, ChemPhysChem 11(1), 90-92 (2010).

${ }^{104}$ M. Neustetter, J. Aysina, F. F. da Silva, and S. Denifl, Angew. Chem., Int. Ed. 54(31), 9124-9126 (2015).

${ }^{105}$ J. Kočišek, K. Grygoryeva, J. Lengyel, M. Fárník, and J. Fedor, Eur. Phys. J. D 70(4), 98 (2016).

${ }^{106}$ C. Huang, V. V. Kresin, A. Pysanenko, and M. Fárník, J. Chem. Phys. 145(10), 104304 (2016).

${ }^{107}$ M. Ončák, R. Meißner, E. Arthur-Baidoo, S. Denifl, T. F. M. Luxford, A. Pysanenko, M. Fárník, J. Pinkas, and J. Kočišek, Int. J. Mol. Sci. 20(18), 4383 (2019). 